\title{
Uji Toksisitas Akut Ekstrak Etanol Buah Wualae (Etlingera elatior (Jack) R. M. Smith) Terhadap Gambaran Histopatologi Organ Jantung Tikus Wistar (Rattus norvegicus)
}

\author{
Asriullah Jabbar, Wahyuni, Muhammad Ilyas Yusuf, Wa Ode Nia Helmia, Sahidin*
}

Fakultas Farmasi Universitas Halu Oleo, Kampus Hijau Bumi Tridharma Anduonohu, Jl. H. E. A. Mokodompit Kendari 93232

E-mail: sahidin02@uho.ac.id

\begin{abstract}
Abstrak
Buah wualae (Etlingera elatior (Jack) R. M. Smith) mengandung senyawa alkaloid, flavonoid, tanin dan terpenoid yang berkhasiat sebagai antioksidan, antibakteri, dan imunomodulator. Penelitian ini bertujuan untuk mengetahui batas keamanan dari ekstrak yang ditinjau dari nilai $\mathrm{LD}_{50}$ dan pengaruhnya terhadap histopatologi organ jantung, paru-paru dan limpa tikus. Jenis penelitian ini adalah penelitian eksperimental yang dilakukan dengan metode Reed-Munch menggunakan 28 ekor tikus yang dibagi ke dalam 4 kelompok perlakuan. Kelompok kontrol diberi NaCMC 0,5\% dan kelompok perlakuan diberi ekstrak dosis $500 \mathrm{mg} / \mathrm{kg} \mathrm{BB;} 5000 \mathrm{mg} / \mathrm{kg} \mathrm{BB}$; dan $15000 \mathrm{mg} / \mathrm{kg} \mathrm{BB}$. Rute pemberian yang digunakan adalah rute oral. Parameter yang diamati dalam penelitian ini adalah nilai LD50, gejala toksik yang timbul sampai tikus mati, dan perubahan bobot tikus, serta pemeriksaan histopatologi organ jantung. Hasil penelitian ini menunjukkan nilai $\mathrm{LD}_{50}$ ekstrak etanol buah wualae adalah $8.649,679 \mathrm{mg} / \mathrm{kg}$ BB (kategori praktis tidak toksik). Pemeriksaan histopatologi organ jantung pada dosis $500 \mathrm{mg} / \mathrm{kg} \mathrm{BB}, 5000 \mathrm{mg} / \mathrm{kg} \mathrm{Bb}$ dan $15000 \mathrm{mg} / \mathrm{kg}$ BB menunjukkan gejala nekrosis.
\end{abstract}

Kata kunci: Etlingera, wualae, hispatologi, organ, kongesti, nekrosis

\section{Pendahuluan}

Indonesia merupakan negara tropis dengan sumber tanaman obat yang berlimpah dan juga merupakan negara dengan keanekaragaman hayati terbesar kedua di dunia, bahkan dapat menjadi posisi pertama jika keanekaragaman hayati laut juga dipertimbangkan [1]. Indonesia memiliki sekitar 25.000-30.000 spesies tanaman. Jumlah tanaman yang digunakan masyarakat Indonesia sebagai obat berjumlah 7.000 spesies dan sebanyak 283 spesies tanaman telah terdaftar di Badan Pengawasan Obat dan Makanan (BPOM) Republik Indonesia [2]).

Salah satu tanaman yang terdapat di hutan tropis Indonesia adalah wualae (Etlingera elatior (Jack.) R. M. SM.) yang di Provinsi Sulawesi Tenggara dikenal dengan nama wualae. Wualae merupakan salah satu tanaman rempah-rempah yang sejak lama dikenal dan dimanfaatkan sebagai bahan obat-obatan [3]. Tanaman wualae memiliki potensi untuk mengobati penyakit-penyakit yang tergolong berat seperti kanker dan tumor [4]. Buah wualae sendiri memiliki aktivitas immunomodulator [5], antioksidan [6, 7, 8, 9], antimikroba [10, 11], dan antipiretik [12].

Suatu senyawa dari suatu tanaman dapat dikatakan aman apabila telah melalui uji toksisitas dengan menggunakan hewan coba dan telah terbukti aman secara klinis untuk dikonsumsi, sehingga sangatlah penting mengetahui potensi ketoksikannya melalui $\mathrm{LD}_{50}$ dan spektrum efek toksiknya [13]. Uji toksisitas adalah suatu uji untuk mendeteksi efek toksik suatu zat pada sistem biologi dan untuk memperoleh data dosis respon yang khas dari sediaan uji. Data yang diperoleh dapat digunakan untuk memberi informasi mengenai derajat bahaya sediaan uji tersebut bila terjadi pemaparan pada manusia, sehingga dapat ditentukan dosis penggunaannya demi keamanan manusia [14].

Tujuan uji toksisitas akut adalah untuk mendeteksi adanya toksisitas suatu zat, menentukan organ sasaran dan kepekaanya, memperoleh data bahayanya setelah pemberian suatu senyawa secara akut dan untuk memperoleh informasi awal yang dapat digunakan untuk menetapkan dosis yang diperlukan untuk uji toksisitas selanjutnya [15].

Evaluasi uji toksisitas tidak hanya mengenai $\mathrm{LD}_{50}$, tetapi juga terhadap kelainan tingkah laku, stimulasi atau depresi sistem syaraf pusat aktivitas motorik dan pernapasan hewan uji untuk mendapatkan gambaran sebab kematian, dapat juga dilengkapi dengan pembuatan preparat histopatologi dari organ yang dianggap memperlihatkan kelainan [16].

Histopatologi sangat penting dalam kaitan dengan diagnosis penyakit karena salah satu pertimbangan dalam penegakan diagnosis adalah melalui pengamatan terhadap jaringan yang diduga terganggu [17]. Beberapa organ yang dapat terpengaruh atau rusak akibat toksisitas suatu zat kimia antara lain jantung, paru-paru dan limpa. Hasil uji toksisitas akut menunjukkan bahwa buah, daun, batang dan rimpang Wualae bersifat sedikit toksik (slightly toxic) dengan nilai $\mathrm{LC}_{50}$ masing-masing sebesar $1302.31 \mu \mathrm{g} / \mathrm{mL}$, 
$1162.84 \mu \mathrm{g} / \mathrm{mL}, 1174.52 \mu \mathrm{g} / \mathrm{mL}$ dan $1074.72 \mu \mathrm{g} / \mathrm{mL}[9]$, sehingga penelitian yang dilakukan bertujuan untuk mengetahui mengetahui nilai $\mathrm{LD}_{50}$, serta mengetahui gambaran histopatologi organ jantung yang terpapar ekstrak etanol buah wualae

\section{Metode}

\subsection{Uтит}

Sampel buah wualae (Etlingera elatior (Jack) R.M. Smith), diperoleh dan dikumpulkan dari kelurahan Sambeani, Kecamatan Abuki, Kabupaten Konawe, Provinsi Sulawesi Tenggara. Hewan uji tikus diperoleh dari Laboratorium Fakultas Kedokteran Universitas Halu Oleo.

\subsection{Preparasi Sampel dan Ekstraksi}

Preparasi dilakukan dengan memotong-motong sampel yang sebelumnya telah dibersihkan, selanjutnya dikeringkan dan dihaluskan hingga menjadi serbuk. Simplisia buah dimaserasi dengan etanol $96 \%$ selama $3 \mathrm{x}$ 24 jam, kemudian disaring untuk mendapatkan filtrat dan residu. Filtrat yang diperoleh kemudian digabungkan dan dipekatkan menggunakan ratory vacum evaporator pada suhu tidak lebih dari $60^{\circ} \mathrm{C}$ sehingga diperoleh ekstrak kental [18].

\subsection{Pengelompokan Hewan Uji}

Hewan uji dikelompokan menjadi 4 kelompok dimana setiap kelompok terdiri dari 7 hewan uji. Kelompok tersebut terdiri dari kelompok perlakuan (dosis 500 $\mathrm{mg} / \mathrm{kgBB}$, dosis $5000 \mathrm{mg} / \mathrm{kgBB}$, dan dosis 15000 $\mathrm{mg} / \mathrm{kgBB}$ ), kelompok kontrol negatif (Na. CMC 0,5\%). Kelompok kontrol negatif digunakan untuk melihat perbandingan efek toksik yang dihasilkan [14].

\subsection{Penentuan Nilai $L D_{50}$}

Penentuan nilai $\mathrm{LD}_{50}$ dilakukan dengan membagi tikus menjadi 4 kelompok perlakuan. Setiap kelompok terdiri dari 7 ekor tikus jantan. Tikus sebelumnya diaklimatisasi terlebih dahulu selama 7 hari. Selama aklimatisasi tikus ditimbang untuk mendapatkan bobot konstan. Pengujian toksisitas akut ini menggunakan 3 tingkat dosis pada 3 kelompok perlakuan, dan 1 kelompok kontrol negatif.

\subsection{Pemeriksaan Histopatologi}

Organ yang akan diperiksa adalah organ jantung, paru-paru dan limpa. Organ yang diambil dicuci terlebih dahulu menggunakan $\mathrm{NaCl}$ 0,9\% kemudian ditimbang berat organ. Organ selanjutnya difiksasi menggunakan larutan formalin $10 \%$. Selanjutnya diamati histopatologinya.

\subsection{Analisis Data}

Data yang diperoleh berupa data kuantitatif dan kualitatif. Data kualitatif berupa data berat badan, uji prilaku, dan makropatologi yang dilakukan dengan mengamati organ jantung. Data kuantatif berupa jumlah hewan yang mati (dianalisisdengan dilakukan perhitungan $\mathrm{LD}_{50}$ dengan metode Reed-Munch untuk memperoleh nilai $\mathrm{LD}_{50}$ ).

\section{Hasil dan Pembahasan}

\subsection{Preparasi dan Ekstraksi}

Pengambilan sampel dilakukan pada waktu pagi hari dan dilakukan preparasi sampel yang diawali dengan pembersihan dan pencucian sampel buah wualae (E. elatior) dengan air yang mengalir bertujuan untuk menghilangkan sisa kotoran yang melengket pada buah wualae. Kemudian dilakukan pengeringan dengan cara diangin-anginkan terhindar dari cahaya matahari langsung dan dilapisi kain hitam. Pengeringan bertujuan mengurangi kadar air dalam sampel sehingga mencegah terjadinya kontaminasi mikroorganisme yang dapat merusak sampel.

Maserasi merupakan proses perendaman sampel dengan pelarut organik yang dilakukan pada suhu ruangan. Pelarut yang digunakan dalam penelitian ini adalah etanol 96\%. Etanol bersifat semipolar sehingga memungkinkan senyawa polar maupun non polar yang terdapat dalam simplisia dapat tertarik dan mudah menguap dengan titik didih $78^{\circ} \mathrm{C}$ sehingga dapat meninggalkan residu yang tinggi [19]. Disamping itu, etanol merupakan pelarut dengan daya ekstraksi terbesar untuk semua bahan dan berbobot molekul rendah seperti alkaloid, saponin dan flavonoid [20].

\subsection{Uji Toksisitas}

Penelitian sebelumnya menunjukan dosis maksimal ekstrak yaitu sebesar $500 \mathrm{mg} / \mathrm{KgBB}$ [21]. Berdasarkan dosis tersebut, kemudian dilakukan pemilihan jumlah dosis yang didasarkan pada kriteria penggolongan sediaan uji toksisitas dan didapatkan dosis sebesar $500 \mathrm{mg} / \mathrm{KgBB}$, $5000 \mathrm{mg} / \mathrm{KgBB}$ dan $15000 \mathrm{mg} / \mathrm{KgBB}$ yang merupakan perwakilan dari tiap kategori toksisitas yaitu cukup toksik, sedikit toksik dan praktis tidak toksik [14]. Sebagai kontrol normal digunakan larutan Na-CMC 0,5\%.

Tabel 1. Gejala efek toksik

\begin{tabular}{cll}
\hline No. & \multicolumn{1}{c}{ Kelompok Tikus } & \multicolumn{1}{c}{$\begin{array}{c}\text { Gejala/Efek Toksik yang } \\
\text { Timbul }\end{array}$} \\
\hline 1. & $\begin{array}{l}\text { Kontrol (Na-CMC } \\
0,5 \%)\end{array}$ & Aktivitas normal \\
\hline 2. & $500 \mathrm{mg} / \mathrm{KgBB}$ & $\begin{array}{l}\text { Aktivitas gerak meningkat, } \\
\text { perubahan perilaku penjilatan. }\end{array}$ \\
\hline 3. & $5000 \mathrm{mg} / \mathrm{KgBB}$ & $\begin{array}{l}\text { Penurunan aktivitas gerak, } \\
\text { perubahan perilaku penjilatan, } \\
\text { serta pernapasan cepat } \\
\text { (trakipnea) }\end{array}$ \\
\hline 4. & $15000 \mathrm{mg} / \mathrm{KgBB}$ & $\begin{array}{l}\text { Penurunan aktivitas gerak, } \\
\text { perubahan perilaku penjilatan, } \\
\text { pernapasan cepat (trakipnea). }\end{array}$ \\
\hline
\end{tabular}

Pengamatan tingkah laku hewan uji secara rutin dilakukan pada saat setelah pemberian ekstrak selama 2 jam. Pengamatan tingkah laku hewan uji meliputi aktivitas gerak (tremor, keaktifan bergerak, dan diam), perubahan 
perilaku (berputar berlebihan dan penjilatan) dan laju pernapasan (bradipnea dan trakipnea) [14]. Tabel 1 telah diketahui respon pada tiap kelompok berbeda-beda tergantung dari jumlah dan dosis ekstrak yang diberikan. Gejala toksik yang terjadi selama pengamatan sangat bervariasi.

\subsection{Penentuan $L D_{50}$}

Hasil pengamatan terhadap jumlah kematian tikus selama 14 hari setelah pemberian ekstrak etanol buah $E$. elatior menunjukkan gejala kematian mulai terjadi pada dosis $5000 \mathrm{mg} / \mathrm{KgBB}$ dan $15000 \mathrm{mg} / \mathrm{KgBB}$ yaitu masingmasing 1 dan 7 ekor. Gejala kematian tidak ditemukan pada dosis terendah ekstrak yaitu $500 \mathrm{mg} / \mathrm{KgBB}$.

Tabel 2. Data jumlah kematian hewan uji

\begin{tabular}{clccc}
\hline No. & \multicolumn{1}{c}{ Dosis } & $\begin{array}{c}\text { Jumlah } \\
\text { Hewan } \\
\text { Uji }\end{array}$ & $\begin{array}{c}\text { Jumlah } \\
\text { Hewan } \\
\text { Mati }\end{array}$ & $\begin{array}{c}\% \\
\text { Kematian }\end{array}$ \\
\hline 1. & $\begin{array}{l}\text { Kontrol } \\
(\text { Na-CMC 0,5 \%) }\end{array}$ & 7 & 0 & 0 \\
2. & $\begin{array}{l}\text { Dosis I } \\
(500 \mathrm{mg} / \mathrm{Kg} \mathrm{BB})\end{array}$ & 7 & 0 & 0 \\
3. & $\begin{array}{l}\text { Dosis II } \\
(5000 \mathrm{mg} / \mathrm{Kg} \mathrm{BB})\end{array}$ & 7 & 7 & $0.14 \%$ \\
4. & $\begin{array}{l}\text { Dosis III } \\
(15000 \mathrm{mg} / \mathrm{Kg} \mathrm{BB})\end{array}$ & & $700 \%$ \\
\hline
\end{tabular}
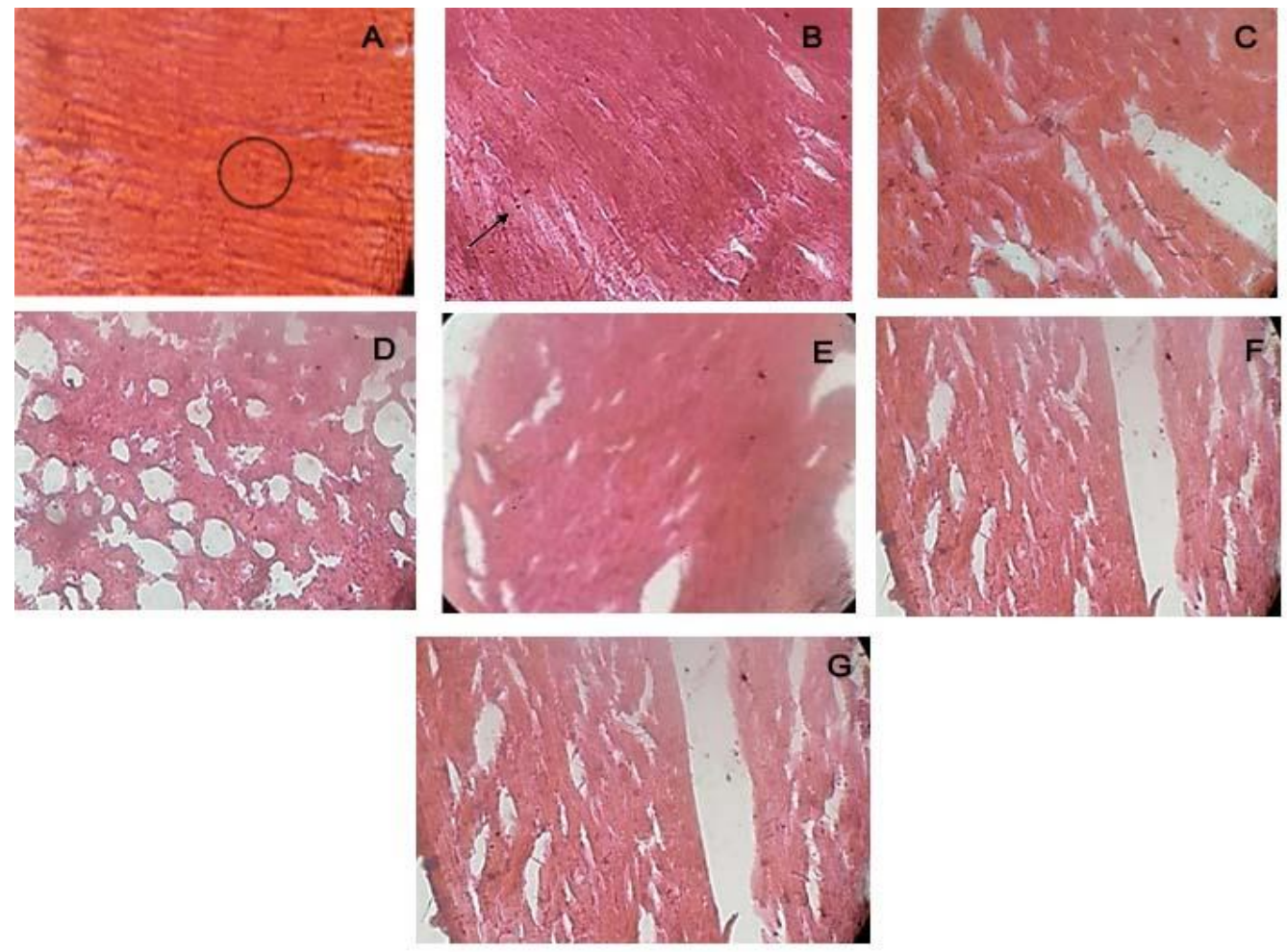

Gambar 1. Gambaran histopatologi organ jantung tikus, pembesaran 100x, pewarna HE; (A) kelompok kontrol negatif; (B) jantung tikus I kelompok dosis I yang mati setelah hari ke-14; (C) jantung tikus II kelompok dosis II yang mati pada hari ke-14; (D) organ jantung tikus III kelompok dosis II yang mati pada hari ke-3; (E) organ jantung tikus II kelompok dosis III yang mati pada hari ke4; (F) organ jantung tikus III kelompok dosis III yang mati pada hari ke-5; (G) organ jantung tikus IV kelompok dosis III yang mati pada hari ke-6 
Hasil pemeriksaan histopatologi organ jantung, paru dan limpa disajikan pada Tabel 3 setelah dilakukan 14 hari pemberian ekstrak buah wualae, organ jantung yang mengalami nekrosis adalah semua tikus pada kelompok II, III dan kelompok IV. Pada kelompok I tidak ada yang mengalami kerusakan (normal).

Hasil histopatologi yang telah dilakukan menunjukkan pada kelompok dosis kontrol yang diberi NaCMC 0,5\% (Gambar 1) memiliki struktur jantung yang mempunyai selsel dalam batas normal. Gambar 1 menunjukkan diskus interkalaris yang merupakan batas atau pertemuan antara dua sel otot. Diskus interkalari ini terlihat seperti garis lurus yang membentuk tangga. Serat otot jantung dibungkus suatu sarkoplasma tipis yang lebih banyak corak garis memanjang lebih jelas karena miofibril-miofibril terpisahpisah oleh deretan mitokondria [24].

Kelompok dosis I (Gambar 2), jaringan jantung menunjukkan struktur jantung dan diantaranya nampak sedikit area nekrotik. Pada kelompok dosis II (Gambar 1c dan 1d) menunjukkan sediaan jaringan jantung menunjukkan struktur jantung dengan sel-sel jantung yang berbeda antara tikus II dan tikus III, pada tikus II struktur jantung sebagian masih normal diantaranya nampak area nekrotik disekitarnyasedangkan pada tikus III mengalami nekrosis yang menunjukkan banyaknya area nekrosis piknotik (inti tampak lebih padat dan berwarna lebih gelap)

Pada kelompok dosis III (Gambar 1e, 1f dan 1g), sediaan jaringan jantung menunjukkan struktur jantung dengan sel-sel jantung hampir semuanya sudah nekrotik. Pada Gambar 1e menunjukkan nekrosis yaitu piknotik, Gambar 1f kerusakan yang terjadi adalah nekrosis kario ereksi inti terbagi atas fragmen-fragmen robek dan pada Gambar 1g menunjukkan kerusakan yang parah yaitu nekrosis piknotik dimana semua hampir semua inti sel tampak lebih padat dan berwarna gelap.

\section{Kesimpulan}

Nilai LD $_{50}$ ekstrak etanol buah wualae 8649,679 $\mathrm{mg} / \mathrm{kg}$ BB (kategori praktis tidak toksik), dan hasil pemeriksaan histopatologi organ jantung pada dosis 500 $\mathrm{mg} / \mathrm{kg} \mathrm{BB}, 5000 \mathrm{mg} / \mathrm{kg} \mathrm{Bb}$ dan $15000 \mathrm{mg} / \mathrm{kg} \mathrm{BB}$ menunjukkan gejala nekrosis.

\section{Ucapan Terima Kasih}

Peneliti mengucapkan terima kasih kepada Kementerian Riset, Teknologi, dan Pendidikan Tinggi (Kemenristekdikti) atas bantuan dana yang diberikan melalui Hibah Penelitian Dasar Perguruan Tinggi Tahun 2019.

\section{Daftar Pustaka}

1. Handa SS, Rakesh DD, Vasisht K, Compendium of Medicinal and Aromatic Plants Volume II Triest: United Nations Industrial Development Organization (UNIDO) International Center For Science and High Technology (ICS), 2006.

2. Dewoto HR, Pengembangan Obat Tradisional Indonesia Menjadi Fitofarmaka. Majalah Kedokteran Indonesia, 2007, 57(7);205-21.
3. Hidayat S, Hutapea S, Inventaris Tanaman Obat Indonesia. Edisi I: 440-441, Jakarta: Badan Penelitian dan Pengembangan Departemen Kesehatan Republik Indonesia, 1991.

4. Chan EWC, Lim YY, Omar M, Antioxidant and antibacterial activity of leaves of etlingera species (Zingiberaceae) in Peninsular Malaysia, Food Chemistry, 2007, 104;1586-1593

5. Wahyuni, Malaka MH, Fristiohady A, Yusuf MI, Sahidin, Potensi imunomodulator ekstrak etanol buah kecombrang (Etlingera elatior (jack) RM Smith) terhadap aktivitas fagositosis makrofag mencit jantan galur Balb/c, Pharmacon, 2017, 6(3);350-355.

6. Jabbar A, Wahyuni, Malaka MH, Apriliani, Aktivitas antioksidan ekstrak etanol buah, daun, batang dan rimpang pada tanaman wualae (Etlingera Elatior (Jack) RM Smith), Jurnal Farmasi Galenika, 2019, 5(2);189-197

7. Sahidin, Wahyuni, Malaka MH, Fristiohady A, Saleh A, Manggau MA, Antibacterial and radical scavenger activities of extract and compounds of wualae (Etlingera elatior) stems from Southeast Sulawesi, IOP Conf. Ser.: Mater. Sci. Eng., 2019, 546.

8. Sahidin, Salsabila S, Wahyuni, Fristiohady A, Imran, Potensi antibakteri ekstrak metanol dan senyawa aromatik dari buah wualae (Etlingera elatior), Jurnal Kimia VALENSI, 2019, 5(1).

9. Leorita M, Mardikasari SA, Wahyuni, Malaka MH, Sartinah A, Sahidin, Aktivitas antioksidan dan toksisitas akut ekstrak etanol buah, daun, batang dan rimpang tanaman wualae (Etlingera elatior (Jack) R.M. Smith), Pharmauho, 2018, 4(2).

10. Wahyuni, Malik F, Ningsih A, Zubaydah WOS, Sahidin, Antimicrobial activities of ethanol extract of wualae (Etlingera elatior (JACK) R.M. Smith), JPMS, 2018, 3(1).

11. Musnina WOS, Wahyuni, Malik F, Timung YO, Sabandar $\mathrm{CW}$, Aktivitas antimikroba ekstrak etanol dan fraksi organik rimpang wualae (Etlingera elatior (Jack) R.M. Smith), Pharmauho, 2019, 5(1).

12. Malik F, Ningsi A, Bafadal M, Saktiani DN, Wahyuni, Uji Efek Antipiretik Ekstrak Etanol Buah Wualae (Etlingera elatior (Jack) R.M. Smith) Terhadap Mencit Jantan (Mus musculus L.) Galur Balb/C, Pharmauho, 2018, 4(1).

13. Wahyono, Hakim L, Nurlaila, Sulistio M, Ilyas R, Uji Toksisitas Akut Ekstrak Etanolik Terstandar dari Kulit Akar Senggugu (Clerodendum serratum L. Moon), Majalah Farmasi Indonesia, 2007, 18(1);1-7.

14. Badan Pengawasan Obat dan Makanan Republik Indonesia, Pedoman Uji Toksisitas Nonklinik Secara In Vivo, Jakarta: Badan Pengawasan Obat dan Makanan, 2014.

15. Soeksmanto A, Simanjuntak P, dan Subroto MA, Uji toksisitas akut ekstrak sarang semut (Myrmecodi pendans) terhadap histologi organ hati mencit. Jurnal Natur Indonesia, 2010, 12(2);152-155.

16. Darmansjah I, Farmakologi dan Terapi, Jakarta: Bagian Farmakologi Fakultas Kedokteran, Universitas Indonesia, 1995.

17. Sharon N, Syariful A, Yuliet Y, Formulasi krim antioksidan ekstrak etanol bawang hutan (Eleutherine palmifolia L. Merr), Natural Sciences: Jurnal of Science and Technology, 2013, 2(3);111-122.

18. Lestari WEW, Pengaruh Nisbah Rimpang dengan Pelarut dan Lama Ekstraksi terhadap Mutu Oleoresin Jahe Merah (Zingiber officinale Var. Rubrum), Skripsi, Institut Pertanian Bogor, 2006.

19. Djamal R, Prinsip-Prinsip Dasar Isolasi dan Identifikasi, Padang: Universitas Baiturrahman, 2012.

20. Usman K, Uji potensi antidiabetik ekstrak etanol buah kecombrang (Etlingera elatior (Jack) R. M. Smith) terhadap 
mencit jantan BALB/c yang diinduksi streptozotocin, Skripsi, Universitas Halu Oleo, 2017.

21. Loomis TA, Toksikologi Dasar, Edisi Ke-3, diterjemahkan oleh Imam Argo Donatos, Semarang: IKIP Semarang Press, 1978.

22. Mescher AI, Histologi Dasar Junqueira, Jakarta: Penerbit EGC, 2011.
23. Widayana IGE, The exposure effect of paraquat dichloride herbicide on human pulmonary fibrosis, Jurnal Majority, 2014, 3(7).

24. Nurhaini R, Rahmawati F, Sunyoto, Gambaran histopatologik limpa tikus betina galur Sprague dawley yang diberi ekstrak etanol akar pasak bumi (Eurycoma longifolia Jack) dan diinduksi 7,12-dimetil benz(a) antrazen. Cerata Journal of Pharmacy Science, 2015, 2(1).

2019 by the authors; This article is an open access article distributed under the terms and conditions of the Creative Commons Attribution License (http://creativecommons.org/ licenses/by/4.0/) 